\title{
Pengembangan Aplikasi UKOM Online untuk Jaminan Mutu Lulusan Perguruan Tinggi di Era Pandemi Covid-19
}

\author{
Hartoto \\ Prodi Pendidikan Guru Sekolah Dasar, Fakultas Ilmu Pendidikan, Universitas Negeri Makassar \\ hartoto@unm.ac.id
}

\begin{abstract}
ABSTRAK
Penelitian pengembangan ini bertujuan (1) menghasilkan produk aplikasi UKOM Online dan (2) mengetahui kebermanfaatan aplikasi UKOM Online yang dihasilkan. Penelitian ini menggunakan model pengembangan Alessi \& Trollip. Uji alpha dilakukan oleh 2 ahli dan uji beta oleh 309 mahasiswa program studi PGSD FIP UNM yang melaksanakan UKOM online. Instrumen pengumpulan data menggunakan pedoman observasi, pedoman wawancara, dan angket. Teknik analisis data menggunakan Teknik deskriptif. Penelitian pengembangan ini menghasilkan produk aplikasi UKOM Online dengan fitur utama fitur manajemen peserta ujian, manajemen soal, manajemen ujian, dan manajemen sertifikat, serta dilengkapi panduan penggunaan aplikasi. Hasil penilaian ahli menunjukkan aplikasi UKOM Online masuk dalam kategori sangat layak untuk digunakan, sementara dari sisi pengguna aplikasi UKOM Online ini dalam kategori sangat bermanfaat. Hal tersebut menunjukkan bahwa aplikasi UKOM Online dapat meningkatkan kualitas penyelenggaraan UKOM secara efektif dan efisien dan tentunya berkontribusi terhadap kontrol mutu lulusan perguruan tinggi di era pandemi Covid-19
\end{abstract}

Kata kunci: UKOM Online, ujian komprehensif, mutu lulusan

ABSTRACT

This development research aims (1) to produce UKOM Online application product and (2) to find out the usefulness of the resulting UKOM Online application. This study used the Alessi \& Trollip development model. The alpha test was carried out by 2 experts and the beta test by 309 PGSD students of FIP UNM who carried out UKOM online. The data collection instruments used observation guidelines, interview guidelines, and questionnaires. Data analysis techniques used descriptive techniques. This development research resulted the UKOM Online application product with the main features of exam participant management, question management, exam management, and certificate management, as well as an application usage guide. The results of the expert assessment show that the UKOM Online application is in the very feasible category to use, while from the user point of view, the UKOM Online application is in the very useful category. This shows that the UKOM Online application can improve the quality of implementing UKOM in an effective and efficient manner and of course contribute to the quality control of college graduates in the era of the Covid-19 pandemic.

Keywords: UKOM Online, Comprehensive Examination, Quality of Graduates

\section{PENDAHULUAN}

Penelitian pengembangan ini dilatar belakangi oleh tidak dapat dilaksanakannya ujian komprehensif di Program Studi PGSD Universitas Negeri Makassar pada era pandemi Covid-19 dimana mahasiswa masih menjalankan perkuliahan dari rumah sehingga mereka berada di daerah masing-masing dan tidak memungkinkan untuk mengikuti ujian komprehensif secara luring di kampus. Sementara ujian komprehensif menjadi salah satu prasyarat untuk dapat mengikuti ujian skripsi sebagai upaya untuk memberikan jaminan atas penguasaan bidang keilmuan PGSD sebelum mereka lulus. Data per 23 Juli 2020 terdapat 312 mahasiswa PGSD masuk daftar tunggu ujian komprehensif sehingga perlu segera dicarikan solusi agar tidak menghambat penyelesaian studi mahasiswa.

Ujian komprehensif merupakan ujian yang dilaksanakan untuk mengukur penguasaan kompetensi mahasiswa pada bidang studinya secara komprehensif dan terpadu. Disebut komprehensif karena menyeluruh, bersifat lengkap dan luas, meliputi seluruh aspek cakupan materi maupun aspek kepribadian mahasiswa seperti kognitif, afektif, maupun psikomotorik (Ratna Wulan and Rusdiana 2014). Tujuan ujian komprehensif adalah untuk (1) mengidentifikasi kompetensi yang dimiliki mahasiswa sebelum menyelesaikan studinya (Damis 2018), (2) menjadi jaminan standar mutu lulusan, (3) memetakan kompetensi calon lulusan, (4) bahan pertimbangan untuk perbaikan kurikulum dan proses pembelajaran. Hal tersebut berujung pada penyiapan lulusan 
yang kompeten siap bersaing di dunia kerja (Muhson, Wahyuni, and Mulyani 2012).

Ujian komprehensif di program studi PGSD FIP UNM dikenal dengan sebutan UKOM lebih menekankan pada penguasaan bidang keahlian di sekolah dasar. Bidang keahlian PGSD disesuaikan dengan capaian pembelajaran lulusan (CPL) sarjana PGSD meliputi Bahasa Indonesia, Matematika, IPA, IPS, PPKn, ditambah kompetensi pedagogi (HDPGSDI 2020).

Aplikasi UKOM Online dikemas dalam bentuk drill dimana mahasiswa diberikan kesempatan untuk melakukan latihan terlebih dahulu sebelum mengerjakan ujian yang sesungguhnya. Tujuan dari latihan tersebut adalah mahasiswa terbiasa dalam menggunakan aplikasi dan mempelajari informasi tanpa kesalahan (Smaldino et al. 2019). Sebagai sebuah tool pembelajaran, maka UKOM Online dikembangkan dengan memperhatikan 12 prinsip multimedia pembelajaran (Mayer 2009). Skor nilai yang diperoleh mahasiswa menggambarkan penguasaan kompetensi mahasiswa di 5 bidang keahlian sekolah dasar. Hal ini dapat digunakan sebagai justifikasi mutu lulusan dala hal kompetensi bidang.

Jaminan mutu lulusan sebagaimana yang disebutkan pada PP No. 19 tahun 2005 pasal 1 butir 4 tentang Standar Kompetensi Lulusan merupakan kualifikasi kemampuan lulusan yang mencakup sikap, pengetahuan dan keterampilan (Departemen Pendidikan Nasional 2005). Hal tersebut dijabarkan lagi dalam Dokumen Standar Kompetensi Lulusan, Sistem Penjaminan Mutu Internal Universitas Negeri Makassar tahun 2017 mengenai rumusan capaian pembelajaran lulusan yang wajib mengacu pada deskripsi pencapaian pembelajaran lulusan KKNI (PPM UNM 2017). Pemetaan komptensi jika dilakukan sebelum mahasiswa lulus bentuknya dapat berupa ujian komprehensif. Namun jika mahasiswa telah lulus, bentuknya dapat berupa tracer study, dua kegiatan ini pada dasarnya memiliki kesamaan tujuan yakni memastikan kompetensi lulusan perguruan tinggi (Rofaida and Gautama 2019). Aplikasi UKOM Online yang dikembangkan dapat memfasilitasi pelaksanaan UKOM secara efektif, efisien dan massif karena prosesnya dilakukan secara daring. Aplikasi UKOM Online dapat memberikan Sekaitan dengan jaminan mutu lulusan tersebut, maka hasil UKOM Online memberikan gambaran peta kompetensi mahasiswa sehingga dapat berkontribusi sebagai kontrol mutu lulusan perguruan tinggi di masa pandemic Covid-19 maupun dalam masa normal nantinya.

\section{METODE PENELITIAN}

Penelitian ini merupakan penelitian pengembangan dengan mengikuti model R\&D Alessi \& Trollip (Alessi and Trollip 2001) dengan tahapan 1) perencanaan, 2) desain, dan 3) pengembangan. Objek dari penelitian ini adalah Universitas Negeri Makassar dengan subjek ujicoba alpha terdiri dari 2 orang ahli untuk menilai kelayakan produk dan subjek ujicoba beta melibatkan 309 mahasiswa untuk menilai kebermanfaatan produk yang dikembangkan. Jenis data yang digunakan berupa data kuantitatif berupa skor penilaian dari ahli dan pengguna, dan data kualitatif yang diperoleh dari saran-saran dari ahli dalam uji alpha. Instrumen yang digunakan berupa pedoman observasi, pedoman wawancara, dan angket. Data kuantitatif dianalisis secara deskriptif dan dikualitatifkan kedalam skala likert empat level yakni sangat layak, layak, kurang layak, dan sangat kurang layak (Mardapi 2008)

Tabel 1 Penilaian Hasil Instrumen dengan Rentang Skor Terhitung

\begin{tabular}{cll}
\hline Nilai & Rentang Skor & Kategori \\
\hline 4 & $\mathrm{x} \geq 3,1$ & Sangat Layak (SL) \\
3 & $3,1>\mathrm{x} \geq 2,5$ & Layak $(\mathrm{L})$ \\
2 & $2,5>\mathrm{x} \geq 1,9$ & Kurang Layak (KL) \\
1 & $\mathrm{x}<1,9$ & Sangat Kurang Layak (SKL) \\
\hline
\end{tabular}


Apliasi UKOM Online ini telah terintegrasi dengan system akademik Universitas Negeri Makassar. UKOM Online dilengkapi dengan buku panduan pengelola dan mahasiswa dalam bentuk teks dan video. Panduan mahasiswa meliputi tata cara pelaksanaan, persiapan sebelum dan pada saat ujian, petunjuk operasional aplikasi, dan cara mengunduh sertifikat kelulusan UKOM Online.

Fitur utama yang terdapat dalam aplikasi UKOM Online adalah fitur manajemen peserta ujian, manajemen soal, manajemen ujian, dan manajemen sertifikat.

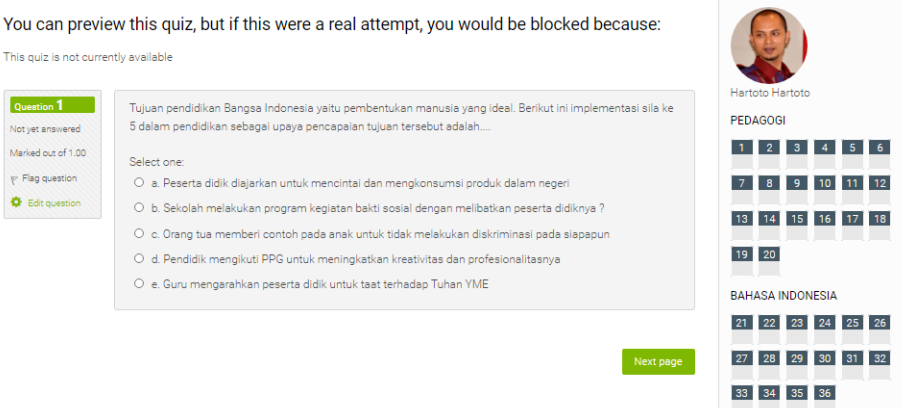

Gambar 1. Tampilan Aplikasi UKOM Online

Manajemen peserta merupakan tempat untuk mengelola peserta dan plotting peserta sesi ujian. Manajemen soal mengelola soal UKOM sesuai bank soal, jumlah soal yang diujikan yakni masing-masing 16 nomor dari Matematika, IPA, IPS, Pkn, dan Bahasa Indonesia, serta 20 nomor pedagogi. Pilihan dan opsi soal ditampilkan secara acak, dan diambil dari bank soal (terdata 413 nomor di bank soal).

Tabel 2 Rekapitulasi Bank Soal UKOM Online

\begin{tabular}{llll} 
No & Kategori & Soal yang Tampil & Bank Soal \\
\hline 1 & Bahasa Indonesia & 16 & 70 \\
2 & Matematika & 16 & 70 \\
3 & IPA & 16 & 70 \\
4 & IPS & 16 & 70 \\
5 & PKn & 16 & 70 \\
6 & Pedagogi & 20 & 63 \\
\hline Total & & $\mathbf{1 0 0}$ & $\mathbf{4 1 3}$ \\
\hline
\end{tabular}

Manajemen ujian untuk melakukan konfigurasi sesi ujian, dan melakukan monitoring ujian. Waktu yang diberikan untuk setiap sesi ujian adalah 120 menit. Melalui aplikasi UKOM Online ini, telah mencapai 858 sesi ujian. Fitur manajemen sertifikat untuk mengelola sertifikat bagi yang mencapai KKM. Sertifikat digital tersebut disertai dengan QRCode unik dan verifikasi sertifikat sehingga keaslian sertifikat dapat diverifikasi oleh publik.

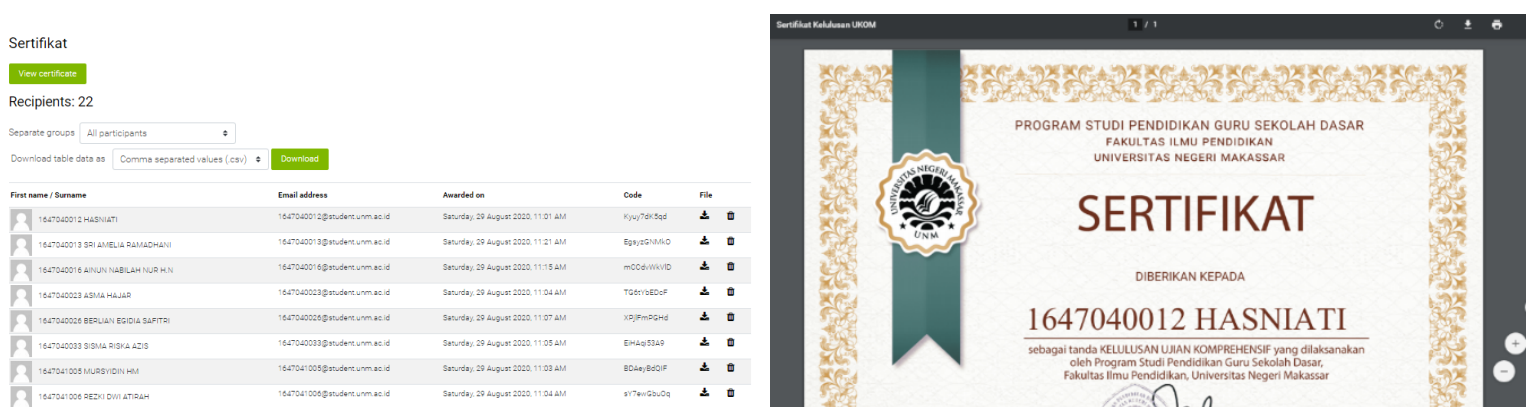

Gambar 2. Tampilan Fitur Manajemen Sertifikat dan Contoh Sertifikat Digital Kelulusan UKOM

Hasil penilaian ahli pada uji alpha menunjukkan aplikasi UKOM Online sangat layak digunakan dengan rerata skor 3.56 dengan rincian aspek program 3.28 (kategori sangat layak), aspek tampilan dengan skor 3.80 (kategori sangat layak), dan aspek panduan dengan skor 4.00 (kategori sangat layak).

Hasil uji beta oleh 309 mahasiswa menunjukkan aplikasi UKOM Online masuk kategori sangat bermanfaat (skor 3.12). Namun 
demikian berdasarkan masukan responden, untuk mengakses aplikasi UKOM online masih perlu ditingkatkan kecepatannya mengingat sebagian besar peserta berada di daerah dengan jangkauan internet yang kurang representatif. Namun demikian, secara umum menunjukkan respon positif terhadap aplikasi UKOM Online yang dikembangan dan mereka gunakan.

Aplikasi UKOM Online dikembangkan dengan serangkaian proses mulai dari tahap perancangan, desain, dan pengembangan. Aplikasi ini telah divalidasi sehingga dinilai layak dan bemanfaat. Aplikasi inipun didukung berbagai teori pengembangan seperti komponen-komponen aplikasi drill (Alessi and Trollip 2001), prinsip-prinsip multimedia (Mayer 2009), user interfaces (Tidwell 2011), user experience (Unger 2012). Uji kelayakan oleh ahli dan uji kebermanfaatan oleh mengguna memberikan justifikasi bahwa aplikasi UKOM Online yang dikembangkan berpotensi untuk diimplementasikan secara meluas.

Aplikasi yang baik tentunya perlu
mendapat dukungan berupa regulasi, infrastruktur, bank soal, dan SOP. Hal tersebut untuk menjamin ekosistem aplikasi dapat tumbuh dan bertahan lama. Regulasi pelaksanaan UKOM memberikan landasan formal terkait proses UKOM yang diselenggarakan agar tidak menimbulkan masalah dikemudian hari. Infrastruktur server dan jaringan yang memadai memberikan pengaruh terhadap kecepatan akses ke aplikasi. Bank soal merupakan alat ukur kompetensi, sehingga perlu senantiasa diperbarui dan diperbanyak agar dapat mengukur secara valid dan reliabel. Dan yang terakhir adalah SOP yang digunakan untuk panduan, kontrol mutu pelaksanaan yang professional. Empat komponen tersebut akan menghasilkan proses penyelenggaraan UKOM yang efektif, efisien, dan transparan.

Hasil UKOM Online memberikan gambaran peta kompetensi yang dimiliki oleh mahasiswa. Kompetensi tersebut meliputi kompetensi pedagogi, Bahasa Indonesia, Matematika, IPA, IPS, dan PKn (HDPGSDI 2020). Peta kompetensi tersebut kemudian dijadikan bahan evaluasi untuk perbaikan kualitas pengajaran, meningkatkan kompetensi yang kurang, dan sebagai dasar untuk kebijakan ditingkat program studi, fakultas, dan universitas. Dengan demikian UKOM Online menjadi salah satu instrumen untuk jaminan mutu lulusan perguruan tinggi terutama di masa Pandemi Covid-19.

\section{KESIMPULAN \& SARAN}

Penelitian pengembangan ini menghasilkan produk aplikasi UKOM Online yang dilengkapi fitur manajemen peserta ujian, manajemen soal, manajemen ujian, dan manajemen sertifikat, serta dilengkapi panduan penggunaan aplikasi. Hasil penilaian ahli menunjukkan aplikasi UKOM Online masuk dalam kategori sangat layak untuk digunakan. Sementara dari sisi pengguna aplikasi UKOM Online ini dalam kategori sangat bermanfaat. Hal tersebut menunjukkan bahwa aplikasi UKOM Online dapat meningkatkan kualitas penyelenggaraan UKOM secara efektif dan efisien dan tentunya berkontribusi terhadap kontrol mutu lulusan program studi. Penelitian selanjutnya diharapkan dapat mengembangkan fitur keamanan dan pengawasan sehingga penyelenggaraan UKOM Online dapat lebih kredibel dan meminimalisir potensi kecurangan pada saat pelaksanaan ujian.

\section{DAFTAR PUSTAKA}

Alessi, Stephen M., and Stanley R. Trollip. 2001. Multimedia for Learning: Methods and Development. 3rd ed. Boston: Allyn and Bacon.

Damis, Rahmi. 2018. "Efektivitas Ujian Komprehensif dalam Meningkatkan Kompotensi Mahasiswa Prodi Ilmu Aqidah." Aqidah-ta: Jurnal Ilmu Aqidah 4(1). doi: 10.24252/aqidahta.v4i1.5173.

Departemen Pendidikan Nasional. 2005. Peraturan Pemerintah Nomor 19 Tahun 2005 Tentang Standar Nasional Pendidikan. Jakarta: Depdiknas.

HDPGSDI. 2020. Capaian Pembelajaran Lulusan (CPL) Sarjana, Magister, Dan Doktor PGSD/Pendidikan Dasar. Makassar: Himpunan Dosen PGSD Indonesia.

Mardapi, Djemari. 2008. Teknik Penyusunan Instrumen Tes Dan Non Tes. Yogyakarta: Mitra Cendikia Press.

Mayer, Richard E. 2009. Multimedia Learning. 2nd ed. Cambridge; New York: Cambridge University Press.

Muhson, Ali, Daru Wahyuni, and Endang Mulyani. 2012. "Analisis Relevansi Lulusan Perguruan Tinggi dengan Dunia Kerja." Jurnal Economia 8:11.

PPM UNM. 2017. Dokumen Standar Komputensi Lulusan Universitas Negeri Makassar. Makassar: Unviersitas Negeri Makassar. 
Ratna Wulan, Elis, and Ahmad Rusdiana. 2014.

Evaluasi Pembelajaran Dengan

Pedoman Kurikulum 2013. Bandung: Pustaka Setia Bandung.

Rofaida, Rofi, and Budhi Pamungkas Gautama. 2019. "Strategi Peningkatan Komptensi Lulusan Perguruan Tinggi Melalui Studi Pelacakan Alumni (Tracer Study)." Image: Jurnal Riset Manajemen 8(1):1-8. doi: 10.17509/image.v7i1.23171.

Smaldino, Sharon E., Deborah L. Lowther, Clif Mims, and James D. Russell. 2019. Instructional Technology and Media for Learning. 12th Edition. New York: Pearson Education, Inc.

Tidwell, Jenifer. 2011. Designing Interfaces: Patterns for Effective Interaction Design. 2. ed. Beijing: O'Reilly.

Unger, Russ. 2012. A Project Guide to UX Design: For User Experience Designers in The Field or in The Making. Second edition. Berkeley, CA: New Riders. 